\title{
DISCURSO DE POSSE NA TITULARIDADE DO DEPARTAMENTO DE DIREITO DO TRABALHO
}

\author{
Sérgio Pinto Martins \\ Professor Titular do Departamento de Direito do \\ Trabalho da Faculdade de Direito da \\ Universidade de São Paulo
}

\author{
Exmo. Sr. Prof. Dr. Guido Fernando Silva Soares, \\ Digníssimo Vice-Diretor da Faculdade de Direito da Universidade de São Paulo \\ Douta Congregação, \\ Exmos. Srs. Professores, \\ Exmos. Srs. Juízes, \\ Senhoras e senhores.
}

Hoje, tenho a felicidade de compartilhar esta posse com o professor Antonio Chaves de Camargo, mestre que batalhou para alcançar a titularidade, que luta diante das adversidades da escola pública para torná-la melhor, atingindo o ápice da carreira, procurando ser um paradigma para seus alunos. O meu reconhecimento nesta data ao mestre, principalmente pelo trabalho que tem feito na Comissão de Pós-graduação.

Toda vez que passo pelo pátio e vejo as arcadas, penso na tradição destas paredes. Por essa escola passaram importantes figuras da nossa nação: políticos, poetas, juízes, juristas.

Para mim é uma grande honra ser professor desta escola. Nunca esperei que isso viesse a acontecer, principalmente na condição de professor titular. Daí a importância de se aproveitar os momentos que nos são reservados pelo destino.

Não me considero exatamente um mestre. "Mestre como afirma Guimarães Rosa não é quem sempre ensina, mas quem de repente aprende" Tenho mais aprendido com as pessoas do que ensinado, procurando trazer a minha experiência.

Minha responsabilidade é suceder na cadeira os insígnes professores desta academia: Cesarino Jr. e Amauri Mascaro Nascimento, que, por certo, não é fácil, seja pelas obras de qualidade destes juristas, seja pela cultura dos referidos professores, que eu não tenho. 
Fui aluno de vários professores desta casa na graduação. Do professor Pedro Vidal duas vezes, em Teoria Geral do Estado e em Direito do Trabalho e também dos professores: Álvaro Villaça Azevedo, durante quase quatro anos, em Direito Civil; Nelson Mannrich, Giselda Novaes Hironaka, em Direito de Família e do professor Guido Silva Soares, em Direito Internacional Privado.

Na pós-graduação fui aluno dos professores Amauri Mascaro, Anníbal Fernandes, Cassio Mesquita Barros, Pedro Vidal, Octávio Bueno Magano, que foi meu orientador no doutorado; Oris de Oliveira e Wagner Giglio. Infelizmente, esses professores se aposentaram e foi necessário recompor o nosso departamento.

Guardo com carinho as lições de vida e a atenção que o professor Ruy Barbosa Nogueira tinha para comigo, quando fui seu aluno no mestrado em Direito Tributário, que ficaram na minha memória. Uma das frases que ele sempre repetia era: "o homem ocupado é o que tem tempo" Dê, portanto, uma atribuição ao homem ocupado, que ele encontrará tempo. A outra era "escrever é por as idéias em ordem"

A função do professor na universidade, além de ministrar a matéria, é de estimular e orientar o aluno, para que ele siga seu próprio caminho, mas, acima de tudo, para fique motivado e estude.

O professor representa aquele sonho, que começa, a maior parte das vezes, com alguém que acredita em você, "que o puxa, empurra para o próximo estágio, às vezes até o aguilhoando com um bastão profundo chamado verdade". Agradeço aos meus professores, que foram bons. $\mathrm{O}$ aluno, porém, não é grande coisa e precisa melhorar.

Meu compromisso, que devo prestar, por tradição, nesta posse, é de lutar por aquilo que acredito, principalmente pela verdade.

É por isso que penso ser necessário falar da reforma previdenciária, pois cabe ao professor contribuir com sua crítica, mas também dar sugestões para o aperfeiçoamento do nosso Direito.

A reforma previdenciária é necessária por quatro motivos: a- o aumento da expectativa de vida do brasileiro; $b$ - o fato de que as mulheres têm um número menor de filhos, diminuindo a arrecadação da contribuição previdenciária; c- a circunstância de haver um menor número de ativos financiando os inativos; d- o desemprego e a informalidade, em que o trabalhador nada paga para o sistema e, dependendo do caso, usa o seguro-desemprego e o sistema de saúde.

O projeto de emenda constitucional estabelece mesmo é reforma 
previdenciária no setor público. Apenas um item é direcionado aos segurados da área privada, elevando o teto das aposentadorias e pensões para $R \$ 2.400,00$.

$O$ teto vai implicar que o sistema arrecade mais num primeiro momento, pois as pessoas irão querer recolher sobre o novo teto para ter direito a um benefício maior, mas não irão se aposentar com valores superiores aos atuais, mas com base no fator previdenciário, que adota a média de $80 \%$ das maiores contribuições a partir de julho de 1994 em diante. No início da sua vida laboral o segurado contribui com valores inferiores aos do teto e, muitas vezes, sobre um salário mínimo.

A reforma transfere o problema para daqui a alguns anos, quando certas pessoas terão condições de se aposentar com valores próximos ao novo teto. Desaparece o propalado déficit do INSS com uma penada, pois praticamente nada está sendo feito para modificar o sistema na área privada.

O estabelecimento do novo teto para futuros servidores públicos importa que o governo vai arrecadar valor inferior da contribuição do servidor, porém vai pagar os antigos funcionários pelo valor do último salário. Isso já mostra que, num primeiro momento, haverá déficit no sistema.

O limite de idade de sessenta anos para o homem e 55 para a mulher existe no setor público, mas não tem correspondente no setor privado, mostrando desigualdade.

Descabido o argumento de que deve existir solidariedade dos aposentados com os demais segurados do sistema, pois se a pessoa já recolheu o suficiente para ter direito ao benefício, não há como se solidarizar a outras pessoas para que estas tenham direito à prestação.

Incabivel a assertiva de que os inativos financiem também os seus próprios benefícios, porque nesse caso não temos contribuição, mas imposto, que é geral, pois o contribuinte nenhuma vantagem tem com o pagamento. Sua aposentadoria não vai ser melhorada com a contribuição vertida após o jubilamento, nem vai ser concedida outra aposentadoria. Não há direito a pecúlio, com a devolução do que já pagou após se aposentar, quando a pessoa parar de trabalhar.

Estabelecer contribuição para o inativo é a mesma coisa que pagar um bem em prestações, quitar a última parcela e continuar a pagar o bem ou então estabelecer contribuição para financiar a aposentadoria da outra encarnação. Não há lógica alguma nisso.

Estranha-se haver contribuição do funcionário público inativo e não ocorrer o mesmo na área privada. Existe, portanto, outra desigualdade. 
O fundamento para se exigir um desconto de $30 \%$ para o cálculo da pensão na área pública e não pagá-la com o valor integral é o fato de que diminuem os gastos na família do segurado com sua morte. Existem, porém, vários tipos de família. Se a família é numerosa, a diminuição de uma pessoa não altera a necessidade de receber a pensão integral, principalmente porque muitos benefícios têm baixo valor. É o que ocorre com famílias de mais de cinco pessoas. As pessoas de idade gastaın mais com remédios e com médicos. Parece que o número utilizado tomou por base apenas quanto seria possível economizar com o pagamento da pensão, que seria de $30 \%$ do que exceder o novo teto.

A pensão por morte na área privada não tem, contudo, alterações no porcentual, mostrando mais uma desigualdade. O sistema tem sido mal administrado, pois os recursos existem. São provenientes da folha de salários, faturamento, lucro, contribuição dos trabalhadores e a receita de concursos de prognósticos, mas eles desaparecem e são empregados para outros fins, como para construção de grandes obras, de subscrição de capital em empresas estatais, para gerar superávit primário para o FMI etc. Não estão sendo combatidas as causas, mas apenas efeitos periféricos. É o mesmo que mandar o doente fazer fisioterapia para se recuperar e não ministrar antiinflämatório para evitar a infecção.

A aposentadoria e a velhice dignas são formas de preservar o princípio da dignidade da pessoa humana, que não está sendo respeitado na reforma.

$\mathrm{O}$ que é mais importante a segurança jurídica das relações ou o aspecto econômico? $\mathrm{O}$ aspecto social que tem a previdência social deve preponderar sobre o ideal econômico. Como nada de concreto foi feito para combater as causas, com exceção do aumento da idade, daqui há a alguns anos haverá necessidade de ser feita outra reforma.

É a idéia de Lampeduza de que é preciso fazer alguma coisa, para que elas permaneçam como estão. Vamos, portanto, fazer a reforma para que as coisas permaneçam como sempre estiveram.

Deixou de ser tomada providência concreta para mudar para melhor a previdência. Na verdade, estamos mesmo diante da imprevidência social, em razão de tantas mudanças no curso do período em que o segurado adquire o direito. Não há, muitas vezes, como estabelecer um planejamento do benefício, pois as regras do sistema mudam constantemente.

Como afirma Goethe: é muito mais fácil reconhecer o erro do que encontrar a verdade; aquele está na superfície e por isso é fácil erradicá-lo; esta repousa no fundo, e não é qualquer um que pode investigá-la. 
O Direito não é só norma, mas também experiência, como ensina o professor Miguel Reale. Nossa experiência em reformas previdenciárias não tem sido satisfatória, porque elas acabam criando outros problemas. Deveríamos reformar para melhorar, inovando para aperfeiçoar o sistema, visando observar o conteúdo social que a previdência tem.

Por fim, quero agradecer certas pessoas que foram importantes nesta etapa. Ao meu pai, Rubens Martins, que sofreu muito ao falecer de câncer, mas que me deixou exemplos de vida.

O primeiro, da sua insistência para que eu estudasse e me esforçasse para aprender e continuar diariamente me aperfeiçoando. $O$ profissional deve ter a firme determinação de continuar se aprimorando e nunca parar de estudar, imbuindose de hábitos metódicos no seu mister. Dizia Dom Quixote àquele lavrador que sonhava com Salamanca: "Tudo na vida é engano, exceto estudar e estudar mais" (Dom Quixote, II, 60). Essa é a determinação que deve ter o profissional, procurando estudar sempre, melhorando suas deficiências, pois "não se pode ter a cabeça erguida sobre os homens, sem antes tê-la baixado sobre os livros"

O segundo, é a persistência no trabalho diário, que não tem hora para terminar e é feito todos os dias. O terceiro, é a perseverança em continuar lutando contra as adversidades para conseguirmos nossos objetivos, porque ele lutou contra os seus problemas até o fim, mesmo que na última vez não o conseguisse.

Se meu pai estivesse aqui presente, estaria contente e emocionado, ao seu modo, como em todos as vezes em que foi nas minhas posses. A minha mãe, Clarice, que também insistiu para que eu estudasse e me deu suporte para fazer o mestrado e o doutorado nesta casa, pelo seu amparo e compreensão nos momentos mais difíceis.

A Marcia, que sofreu comigo em várias oportunidades, inclusive durante o concurso para professor titular, pela sua paciência. Essa vitória também é sua. A Mariana, que sabia de cor muitas passagens da minha tese, O pluralismo do Direito do Trabalho, tantas vezes lhe foram repetidas. Que lhe sirva o exemplo de estudo, para que possa cursar aquilo que desejar e atingir seus objetivos.

A minha sogra, Tereza, que representa minha segunda mãe, tamanha a sua preocupação e consideração em relação à minha pessoa. Agradeço a saudação do professor Mannrich. O homem rico, em inglês. Ele sempre responde: o homem rico de amigos.

Um amigo certo durante a vida já é bastante. Reconhece-se o amigo não só nos bons momentos, mas principalmente nos momentos incertos. “Amigas - portanto 
- são aquelas raras pessoas que nos perguntam como estamos e que depois ficam à espera para ouvir a resposta"

Agradeço aos nossos amigos que aqui compareceram esta noite.

São Paulo, dezembro de 2003.

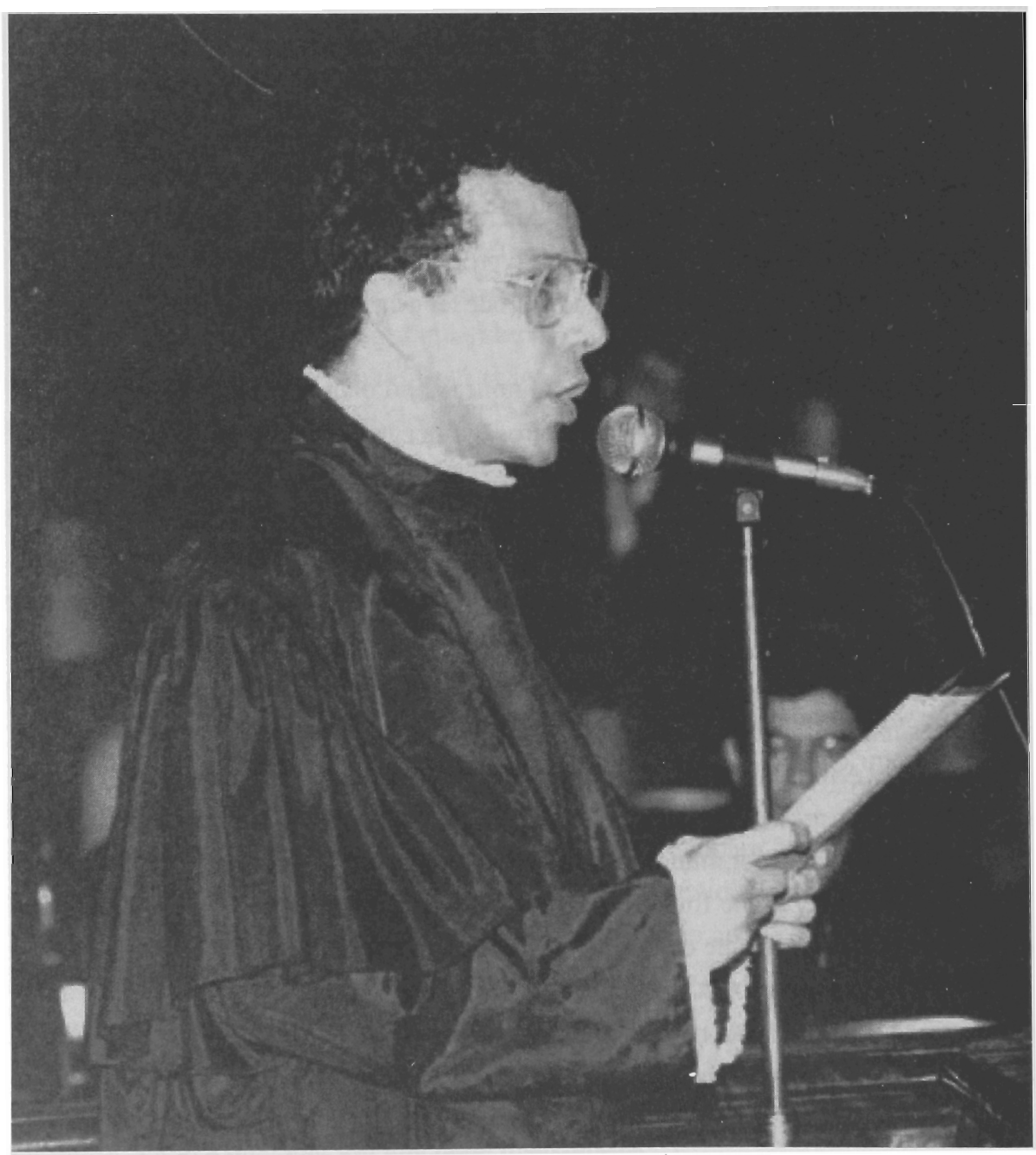

Professor Titular Sérgio Pinto Martins 